\title{
Características morfofisiológicas de sementes e produção de girassol em função de boro no solo ${ }^{1}$
}

\author{
$\overline{\text { Gisele A. Bonacin², Teresinha de J. D. Rodrigues }}{ }^{3}$, Mara C. P. da Cruz $^{3} \&$ David A. Banzatto $^{3}$
}

\begin{abstract}
RESUMO
Com o objetivo de se estudar o efeito de doses de boro sobre as características morfofisiológicas de sementes e a produção de girassol, cultivar Embrapa V122-2000, instalou-se um experimento em 17/11/2000, em área experimental da UNESP/ FCAV, Jaboticabal, SP, em Latossolo Vermelho eutrófico de textura média. O delineamento foi o de blocos casualizados, com cinco doses de boro $\left(0,1,2,3\right.$ e $\left.4 \mathrm{~kg} \mathrm{ha}^{-1}\right)$ em quatro repetições. Após o florescimento pleno (80-90\% de flores abertas) se avaliaram semanalmente, as características das sementes: comprimento, largura e espessura, massa seca, concentração e conteúdo de água, primeira contagem da germinação, germinação final e teor de óleo. Pelos resultados obtidos não se constatou efeito significativo da aplicação de boro nas características das sementes avaliadas aos 49 dias após o florescimento pleno da cultura, o que foi atribuído ao teor inicial de boro no solo, 0,22 $\mathrm{mg} \mathrm{dm}^{-3}$ (extraído com solução de $\mathrm{BaCl}_{2} 1,25 \mathrm{~g} \mathrm{~L}^{-1}$ ) que, além de considerado médio, deve ter sido suficiente para o crescimento e desenvolvimento das sementes de girassol. A produtividade média foi de $2.559 \mathrm{~kg} \mathrm{ha}^{-1}$.
\end{abstract}

Palavras-chave: Helianthus annuus, aquênios, crescimento, micronutriente

\section{Morphophysiological characteristics of seed and production of sunflower as a function of boron in soil}

\begin{abstract}
An experiment was carried out in order to evaluate effects of boron applied to soil on the morphophysiological characteristics of sunflower seed (achene). The experiment was installed on November 17, 2000 in an experimental area at São Paulo State University - UNESP/FCAV, Jaboticabal, SP, in an oxisoil with the sunflower variety Embrapa V122-2000. The experimental design was a completely randomized block, with five doses of boron $\left(0,1,2,3\right.$ and $\left.4 \mathrm{~kg} \mathrm{ha}^{-1}\right)$ with four replications. After full bloom (80-90\% of open flowers), the following characteristics were evaluated during seven weeks: length, width and thickness, seed dry mass, water concentration and content, first counting of germination, final germination and oil content. Seed yield was also evaluated. There was no significant effect of boron application on seed characteristics evaluated 49 days after full bloom, and this result was associated to the initial content of boron in the soil $\left(0.22 \mathrm{mg} \mathrm{dm}^{-3}\right.$ extracted with $\left.\mathrm{BaCl}_{2} 1.25 \mathrm{~g} \mathrm{~L}^{-1}\right)$, which is considered an average value. The mean yield of seeds was $2,559 \mathrm{~kg} \mathrm{ha}^{-1}$.
\end{abstract}

Key words: Helianthus annuus, achenes, growth, micronutrient

1 Parte da Tese de Doutorado apresentada pela primeira autora à FCAV/UNESP

${ }^{2}$ Av. Goiás, 501, Centro, CEP 86380-000. Andirá, PR. Fone: (43) 3538-1425. E-mail: gibonacin@yahoo.com.br

3 FCAV/UNESP, Via de Acesso Paulo Donato Castellane, CEP 14884-900, Jaboticabal, SP. Fone: (16) 3209-2600. E-mail: tedelro@fcav.unesp.br; mcpcruz@fcav.unesp.br; banzatto@netsite.com.br. 


\section{INTRODUÇÃO}

O girassol (Helianthus annuus L.) originário do sudoeste do México, onde cresce em estado natural, foi introduzido na Europa no século 16 como planta cultivada, e reintroduzido na América, a partir da Europa, no século 19 (Salunke \& Desai, 1986). Pertence à família Asteraceae, gênero Helianthus L., que compreende 62 espécies (USDA, 2006). Em 2004, os maiores produtores mundiais de girassol foram a Rússia, com 16,5\% da produção mundial, a Argentina, com 15,325\% e a União Européia, com 14,81\%, com uma produção mundial total em torno de 26 mil t (Agrianual, 2005).

O consumo no Brasil, especialmente do óleo de girassol, tem crescido muito, impulsionado por sua ótima qualidade nutricional. A cultura ganhou grande importância a partir da comprovação da excelente qualidade do óleo comestível extraído de suas sementes (Andrade, 1994). Além de ser matéria-prima de outros alimentos, medicamentos, cosméticos e corantes, o girassol também é fonte protéica para a produção de silagem.

Analisando o cenário nacional, constata-se que a cultura do girassol pode ser utilizada como combustível, apresentando viabilidade técnico-ambiental, com o Governo Federal como incentivador na utilização do biodiesel na matriz energética nacional.

Apesar da ampla adaptação às condições climáticas, ela se desenvolve mais adequadamente em solo fértil e é uma cultura sensível à deficiência de boro (Ungaro, 1990), a qual resulta na inibição do crescimento da cultura (Römheld, 2001). Por outro lado, a toxicidade desse micronutriente também limita o crescimento, o rendimento e a qualidade das sementes (Pathak \& Singh, 1975; Fageria et al., 2002).

De acordo com Hanson (1991) o boro exerce papel importante no processo de florescimento e na formação da semente. Dentre as funções desempenhadas pelo boro se destaca a participação na formação das paredes celulares, na germinação do pólen, na divisão celular, no florescimento e na frutificação (Fageria et al., 1997).

Os sintomas de deficiência de boro nas plantas surgem primeiro nos órgãos mais jovens, com a morte dos brotos terminais, na maioria dos casos. No girassol, a deficiência de boro é notada, comumente, em folhas novas como nos capítulos, os quais são pequenos, deformados e com grãos chochos na região central (Castro et al., 1997). A deficiência de boro, mesmo em casos não muito severos, provoca a deformação dos capítulos e compromete a viabilidade das sementes (Connor \& Hall, 1997).

A relação entre qualidade de sementes de girassol e adubação com nutrientes como nitrogênio, fósforo e potássio, já foi avaliada por vários autores (Lima et al., 1981; Calarota \& Carvalho, 1984), mas os estudos dos efeitos da adubação com boro geralmente se limitam à avaliação da resposta de produção sem avaliação da qualidade da semente.

Para a maioria das espécies, a exigência nutricional em boro se torna mais intensa com o início da fase reprodutiva e mais crítica por ocasião da formação das sementes (Carvalho \& Nakagawa, 2000). A utilização de sementes de boa qualidade é fator imprescindível para o estabelecimento da cultura do girassol e esta qualidade vai depender das condições em que a planta foi cultivada.

Diante do exposto, o objetivo do trabalho foi estudar os efeitos de doses de boro sobre as características morfofisiológicas das sementes e a produção de plantas de girassol.

\section{MATERIAL E MÉTODOS}

O trabalho foi conduzido em área experimental do Departamento de Biologia Aplicada à Agropecuária da FCAV/ UNESP, Jaboticabal, SP, situado a uma altitude de $595 \mathrm{~m}$ acima do nível do mar, latitude de $21^{\circ} 15^{\prime} 22^{\prime}$ S, longitude $48^{\circ} 18$ ' 58” W), em Latossolo Vermelho eutrófico de textura média (Santos et al., 2006).

Os resultados das análises químicas do solo, segundo métodos descritos por Raij et al. (2001) foram: $\mathrm{pH}\left(\mathrm{CaCl}_{2}\right)=4,4$; $\mathrm{P}($ resina $)=28 \mathrm{mg} \mathrm{dm}^{-3} ;$ matéria orgânica $=22 \mathrm{~g} \mathrm{dm}^{-3} ; \mathrm{K}=$ $2,0 \mathrm{mmol} \mathrm{dm}{ }^{-3} ; \mathrm{Ca}=14 \mathrm{mmol} \mathrm{dm}^{-3} ; \mathrm{Mg}=4 \mathrm{mmol}_{\mathrm{C}} \mathrm{dm}^{-3}$; $\mathrm{H}+\mathrm{Al}=42 \mathrm{mmol}_{\mathrm{C}} \mathrm{dm}^{-3} ; \mathrm{SB}=20 \mathrm{mmol}_{\mathrm{C}} \mathrm{dm}^{-3} ; \mathrm{CTC}=$ $62 \mathrm{mmol}_{\mathrm{c}} \mathrm{dm}^{-3}$ e V $=32 \%$. Antes da aplicação dos tratamentos havia no solo o teor médio de boro de $0,22 \mathrm{mg} \mathrm{dm}^{-3}$, extraído com solução de $\mathrm{BaCl}_{2}$ 1,25 g L-1 (Abreu et al., 1994); devido ao baixo teor de magnésio do solo efetuou-se uma calagem com calcário dolomítico 40 dias antes da semeadura, de modo a elevar a saturação de bases do solo para 70\% (Raij et al., 2001).

Antes da semeadura e com o auxílio de um regador manual, procedeu-se a uma única aplicação de solução de ácido bórico $\left(\mathrm{H}_{3} \mathrm{BO}_{3}-17,48 \%\right.$ de boro) na linha da semeadura, de acordo com os tratamentos preestabelecidos.

Fez-se a semeadura em 17/11/2000, utilizando-se sementes recém-colhidas da variedade Embrapa 122-V2000, com teor inicial de 5,4\% de água, previamente mantidas 20 dias em câmara fria a $\pm 5{ }^{\circ} \mathrm{C}$ para quebrar a dormência. A adubação de plantio foi efetuada de acordo com as recomendações de Quaggio \& Ungaro (1996), aplicando-se $10 \mathrm{~kg} \mathrm{~N} \mathrm{ha}^{-1}$, $30 \mathrm{~kg} \mathrm{P}_{2} \mathrm{O}_{5}$ ha $^{-1}$ e $30 \mathrm{~kg} \mathrm{~K}_{2} \mathrm{O}$ ha-1, nas formas de uréia, superfosfato simples e cloreto de potássio, respectivamente. A adubação de cobertura foi realizada aos 30 dias após a emergência (20 kg N ha-1 de na forma de uréia) e os demais tratos culturais constaram de duas capinas manuais durante o ciclo.

O delineamento experimental em campo foi o de blocos casualizados, com cinco tratamentos $(0,1,2,3$ e 4 kg B ha-1) e quatro repetições; as parcelas experimentais apresentavam 5,6 x 9,0 m (50,40 $\left.\mathrm{m}^{2}\right)$ e eram constituídas de 7 linhas de $9 \mathrm{~m}$, espaçadas $0,80 \mathrm{~m}$ entre si e $0,25 \mathrm{~m}$ entre plantas. Foram consideradas bordadura as plantas das duas linhas externas e aquelas distantes $0,5 \mathrm{~m}$ das extremidades das cinco linhas restantes, as duas linhas centrais para a avaliação da produção final e as demais para as coletas semanais.

A partir do estádio R5.8/R5.9, fase com 80 a 90\% de flores abertas (Schneiter \& Miller, 1981), coletas de quatro capítulos por parcela foram realizadas, em intervalos de sete dias (7, 14, 21, 35, 42, e 49 dias após o florescimento pleno).

Os capítulos foram cortados, colocados em sacos plásticos etiquetados e levados rapidamente ao laboratório, onde as sementes foram separadas, as quais corresponderam aos 
aquênios (frutos secos indeiscentes constituídos de pericarpo e semente) do girassol.

Dimensões (comprimento, largura e espessura): Em cada coleta e com o auxílio de um paquímetro, foram medidos o comprimento, a largura e a espessura das sementes, considerando-se oito repetições de 25 sementes para cada dose de boro aplicado.

Massa seca: Para cada repetição do experimento considerou-se a média de três avaliações com 50 sementes, dividindo-se a massa seca pelo número de sementes da amostra.

Teor e conteúdo de água: As características teor, concentração e conteúdo de água são utilizadas para expressar o estado hídrico das sementes. O teor de água (g de água por $\mathrm{kg}$ de semente) difere do teor de água (\%) apenas na maneira de expressar os valores como, por exemplo, para o teor de água de $85 \%$ tem-se a concentração de 850 g de água por kg de semente. Face ao exposto, optou-se pela apresentação dos dados na forma de concentração de água (g de água por kg de semente).

Determinou-se a concentração de água a partir da fórmula:

$$
\mathrm{Cc}_{\text {agua }}=\frac{(\mathrm{MU}-\mathrm{MS}) \times 1000}{\mathrm{MU}}
$$

em que:

$$
\begin{aligned}
\text { Cágua - Concentração de água, g de água por kg de se- } \\
\text { mente } \\
\text { MU - massa úmida } \\
\text { MS - massa seca }
\end{aligned}
$$

Determinou-se o conteúdo de água a partir da fórmula:

$$
\mathrm{Ct}_{\text {agua }}=\frac{\left(\mathrm{MU}_{\mathrm{n}}-\mathrm{MS}_{\mathrm{n}}\right) \times 1000}{\mathrm{n}}
$$

em que:

$$
\begin{aligned}
& \text { Ctágua - Conteúdo de água, mg por semente } \\
& \mathrm{MU}_{\mathrm{n}} \text { - massa úmida de } \mathrm{n} \text { sementes } \\
& \mathrm{MS}_{\mathrm{n}} \text { - massa seca de } \mathrm{n} \text { sementes } \\
& \mathrm{n} \text { - número de sementes da amostra }
\end{aligned}
$$

Germinação nos $4^{0}$ e $1^{\circ}$ dias: Considerou-se a média de quatro avaliações de 30 sementes para cada repetição. As sementes foram colocadas para germinar em caixa de plástico do tipo "gerbox", utilizando-se como substrato areia lavada e esterilizada, sendo realizadas duas contagens, aos quatro e dez dias após o início do teste. Durante toda a condução do experimento utilizou-se temperatura de $25^{\circ} \mathrm{C}$ e fotoperíodo de $16 \mathrm{~h}$. Para o umedecimento inicial da areia calculou-se a quantidade de água necessária para 60\% da capacidade de retenção de água da areia (Brasil, 1992) e se procedeu ao reumedecimento, sempre que necessário.

Teor de óleo: Foi determinado a partir de $1 \mathrm{~g}$ de sementes maceradas e embaladas com papel filtro, por arraste, com a utilização de éter sulfúrico. Por diferença de peso do balão volumétrico obteve-se o teor de óleo (Silva, 1990). Quatro repetições para cada dose de boro foram avaliadas.

Produtividade: No final do ciclo (103 dias após a semeadura) foram colhidas as duas linhas centrais de cada par- cela foram colhidas para obtenção da produtividade, corrigindo-se para a umidade padrão de 11\% (Castiglioni, 1997).

\section{Análise estatística dos resultados}

Os resultados das avaliações semanais foram submetidos à análise estatística (programa ESTAT - Sistema para Análises Estatísticas V.2.0, com base nas médias de sementes originadas de quatro plantas de cada parcela. A partir de análises de regressão para cada semana individualmente, verificou-se que não ocorreu relação definida (significância) nas características avaliadas em função das doses de boro. Partiu-se então para a análise de variância para cada característica e o teste de comparação de médias. As médias obtidas para cada característica nas amostragens foram comparadas pelo teste de Tukey a 5\% de probabilidade (Banzatto \& Kronka, 2006).

Para a análise estatística dos resultados de germinação (primeira e última contagens), os dados foram transformados em arcoseno $\sqrt{x+1}$ e as médias comparadas pela aplicação do teste de Tukey a 5\% de probabilidade (Banzatto \& Kronka, 2006).

\section{RESULTADOS E DISCUSSÃO}

A produção e as características morfológicas das sementes de girassol não sofreram alterações significativas dos tratamentos. Possivelmente, o teor médio inicial de boro no solo $\left(0,22 \mathrm{mg} \mathrm{dm}^{-3}\right)$ e a adequada disponibilidade de água (838,9 mm) durante o período experimental, tenham proporcionado condições de crescimento e desenvolvimento suficientes às exigências da cultura. Para Menezes \& Marchezan (1991) o estresse hídrico influencia no tamanho das sementes de girassol porém isto não ocorreu durante o experimento, pois foi boa a distribuição de água durante o todo ciclo da cultura, com precipitação acumulada de $850 \mathrm{~mm}$.

Nas condições em que foi desenvolvido o experimento, a produção média de sementes foi de $2559 \mathrm{~kg} \mathrm{ha}^{-1}$. Caletti \& Vázquez-Amábile (2002) trabalharam com três híbridos de girassol em solos da Argentina, sob dose de boro entre 0 a $7 \mathrm{~kg} \mathrm{ha}^{-1}$ e teor inicial no solo de 0,8 a $1 \mathrm{mg} \mathrm{dm}^{-3}$ e obtiveram produções entre 2003 e $2539 \mathrm{~kg} \mathrm{ha}^{-1}$. A nível de produtor, as produções obtidas em alguns locais do Estado de São Paulo foram 1218 (EMBRAPA, 1999) e $1990 \mathrm{~kg} \mathrm{ha}^{-1}$ na região Sul do Brasil (EMBRAPA, 1997).

Verificaram-se, nas sete semanas de avaliação, valores médios de comprimento, largura e espessura, entre 1,09 a $1,19 \mathrm{~cm} ; 0,43$ a $0,64 \mathrm{~cm}$ e 0,20 a $0,41 \mathrm{~cm}$, respectivamente, sendo os valores menores verificados naquelas colhidas sete dias após o florescimento pleno (início da formação das sementes). Os valores médios de comprimento estão dentro da variação em dimensões de sementes de girassol, citada por Seiler (1997), ou seja, de 0,70 a 2,5 cm de comprimento e 0,40 a $1,3 \mathrm{~cm}$ de largura.

Aos 42 e 49 dias após o florescimento pleno, a produção média de massa seca variou de 60,17 a 68,89 mg por semente, portanto, semelhante à média de massa seca de sementes da variedade estudada (Embrapa 122-V2000), que é de 60 mg 
por semente (EMBRAPA, 1997), e dentro da faixa de 40 a $400 \mathrm{mg}$ apresentada por Seiler (1997).

O aumento dos níveis de boro aplicados com o teor médio inicial no solo de $0,22 \mathrm{mg} \mathrm{ha}^{-1}$, não influenciou as características das sementes de girassol. Andrade (2000), trabalhando com aplicação de doses de boro $(0 ; 0,75 ; 1,5$ e $\left.2,25 \mathrm{~kg} \mathrm{ha}^{-1}\right)$, não obteve resposta significativa de produção quando o teor de boro no solo era igual a $0,25 \mathrm{mg} \mathrm{dm}^{-3}$.

Diferenças na massa seca individual de sementes ocorreram apenas aos sete dias após o florescimento pleno, quando se obteve, com 1 e $4 \mathrm{~kg} \mathrm{ha}^{-1}$ de boro obteve-se maior massa seca que sem a aplicação de boro. Para Schon (1989), a adubação com boro pode resultar em $18 \%$ de aumento na massa de sementes por planta. Dos 14 aos 49 dias após o florescimento pleno, a massa seca não diferiu sob as doses de boro. Aitken et al. (1987) verificaram que, a partir de $0,2 \mathrm{mg} \mathrm{kg}^{-1}$ de boro no solo, não houve diferenças na massa seca do girassol, concordando com as observações no presente trabalho em relação ao teor médio inicial de boro no solo.

$\mathrm{O}$ aumento de boro a partir de $3,0 \mathrm{~kg} \mathrm{ha}^{-1}$ inibiu linearmente a massa seca das sementes avaliada aos 49 dias após o florescimento pleno das plantas (Figura 1). Alguns autores recomendam a aplicação entre 1,0 a $2,0 \mathrm{~kg} \mathrm{ha}^{-1}$ de boro no girassol (Silva, 1990; Castro et al., 1997), porém as doses do boro não afetaram significativamente a massa seca nem as dimensões das sementes (comprimento, largura e espessura).

Verificou-se, a partir de análises de regressão para cada semana individualmente, que não ocorreu relação definida no conteúdo e concentração de água das sementes de girassol em função das doses de boro.

Realizou-se, então, a análise de variância para cada característica; durante as amostragens e as médias foram comparadas pelo teste de Tukey a 5\% de probabilidade.

Os valores variaram para cada data amostrada; aos sete dias, o maior conteúdo de água foi observado na dose de $1 \mathrm{~kg} \mathrm{ha}^{-1}$,

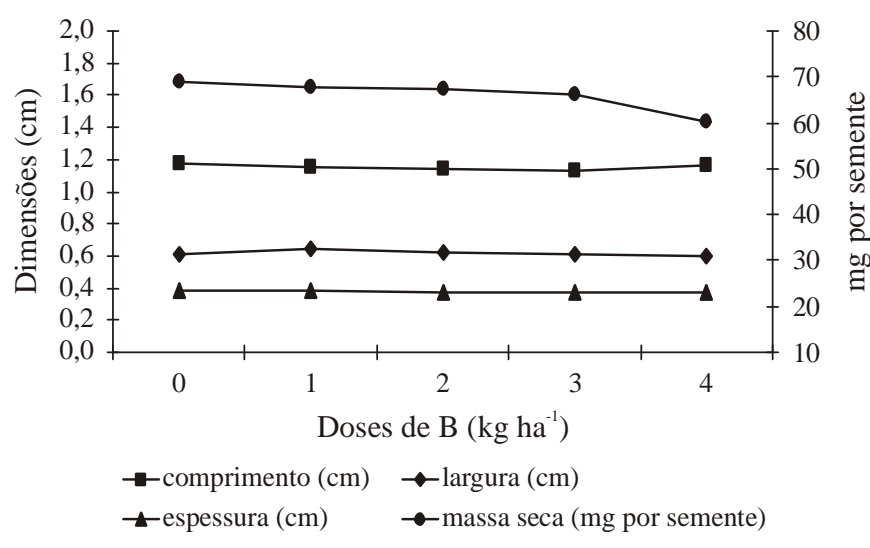

Figura 1. Comprimento, largura, espessura e massa seca de sementes de girassol Embrapa 122-V2000 cultivado sob doses de boro aos 49 dias após o florescimento pleno.

enquanto aos 28 dias, além da dose de $1 \mathrm{~kg} \mathrm{ha}^{-1}, 4 \mathrm{~kg} \mathrm{ha}^{-1}$ proporcionaram também elevação do conteúdo de água nas sementes (Tabela 1). De acordo com Carvalho \& Nakagawa (2000) a semente, logo após ter sido formada tem, normalmente, alto teor de água (ou concentração de água), oscilando entre 70 e $80 \%$ (700 a $800 \mathrm{~g}$ de água por kg de semente), o que ocorreu com a concentração de água, que variou entre 775,95-853,13 (14 DAF) e 724,36-772,20 (21 DAF) (Tabela 1).

Os valores de germinação das sementes na primeira contagem foram menores aos sete dias após o florescimento pleno, variando de 0 a $0,65 \%$; aos 14 e 42 dias, foram registradas diferenças significativas entre os dados, em função das doses de boro, sendo $2 \mathrm{~kg} \mathrm{ha}^{-1} \mathrm{e} 1 \mathrm{~kg} \mathrm{ha}^{-1}$, responsáveis pelos maiores valores aos 14 e 42 dias, respectivamente (Tabela 2). Como a primeira contagem da germinação é um teste de vigor, esses períodos e doses poderiam proporcionaram, respectivamente, o maior vigor nas sementes de girassol.

Quanto à germinação no $10^{\circ}$ dia, constata-se também que

Tabela 1. Conteúdo e concentração de água em sementes de girassol Embrapa 122-V2000 cultivado sob doses de bo ro

\begin{tabular}{|c|c|c|c|c|c|c|c|}
\hline \multirow{2}{*}{ Boro (kg ha-1) } & \multicolumn{7}{|c|}{ Dias após o florescimento pleno (DAF) } \\
\hline & 7 & 14 & 21 & 28 & 35 & 42 & 49 \\
\hline & \multicolumn{7}{|c|}{ Conteúdo de água (mg por semente) } \\
\hline 0 & $70,66 \mathrm{~b}$ & 106,97 a & 97,95 a & $63,28 \mathrm{~b}$ & 59,25 a & $30,50 \mathrm{a}$ & $11,95 \mathrm{a}$ \\
\hline 1 & 89,78 a & $110,97 \mathrm{a}$ & 96,80 a & 80,21 a & 59,65 a & $28,97 \mathrm{a}$ & $12,09 \mathrm{a}$ \\
\hline 2 & $84,48 a b$ & $104,79 \mathrm{a}$ & $105,76 \mathrm{a}$ & $74,04 a b$ & $58,94 a$ & $28,05 \mathrm{a}$ & $11,25 \mathrm{a}$ \\
\hline 3 & $82,63 a b$ & 102,27 a & 98,53 a & $69,18 a b$ & 61,35 a & 31,15 a & $11,38 \mathrm{a}$ \\
\hline 4 & $82,41 a b$ & 104,93 a & 94,74 a & 77,18 a & $66,38 \mathrm{a}$ & 33,87 a & $11,39 \mathrm{a}$ \\
\hline DMS (5\%) & 15,58 & 20,81 & 18,61 & 13,49 & 10,64 & 10,67 & 2,53 \\
\hline $\mathrm{F}$ & $3,34 *$ & $0,40 \mathrm{~ns}$ & $0,83 \mathrm{~ns}$ & $4,07 * *$ & $1,39 \mathrm{~ns}$ & $0,75 \mathrm{~ns}$ & $0,38 \mathrm{~ns}$ \\
\hline \multirow[t]{2}{*}{ CV $(\%)$} & 13,22 & 13,66 & 13,11 & 12,90 & 12,11 & 24,28 & 15,13 \\
\hline & \multicolumn{7}{|c|}{ Concentração de água (g água por kg semente) } \\
\hline 0 & 885,09 a & 853,13 a & $772,20 \mathrm{a}$ & $573,44 a$ & $503,27 a$ & 313,51 a & 147,78 a \\
\hline 1 & $872,01 a b$ & 775,95 a & $724,36 a$ & $609,28 \mathrm{a}$ & $497,08 \mathrm{a}$ & $316,25 a$ & $146,15 a$ \\
\hline 2 & $877,44 a b$ & 839,27 a & 738,23 a & $601,85 a$ & 488,53 a & 301,07 a & 143,69 a \\
\hline 3 & $873,55 a b$ & 844,09 a & $735,90 \mathrm{a}$ & 608,96 a & 512,37 a & 318,94 a & 157,16 a \\
\hline 4 & $867,98 \mathrm{~b}$ & $838,27 \mathrm{a}$ & $736,20 \mathrm{a}$ & $641,81 \mathrm{a}$ & $514,65 \mathrm{a}$ & 339,94 a & $157,16 \mathrm{a}$ \\
\hline DMS (5\%) & 13,33 & 132,07 & 49,23 & 70,29 & 73,25 & 64,90 & 19,37 \\
\hline $\mathrm{F}$ & $3,90 *$ & $0,90 \mathrm{~ns}$ & $2,23 \mathrm{~ns}$ & $1,99 \mathrm{~ns}$ & $0,36 \mathrm{~ns}$ & $0,78 \mathrm{~ns}$ & $1,78 \mathrm{~ns}$ \\
\hline CV (\%) & 1,06 & 11,07 & 4,62 & 8,06 & 10,13 & 14,20 & 8,96 \\
\hline
\end{tabular}

Médias seguidas da mesma letra na coluna não diferem significativamente pelo teste de Tukey

* Significativo a $5 \%$ de probabilidade, ns - não significativo 
Tabela 2. Valores médios de germinação nos $4^{\circ}$ (primeira contagem) e $10^{\circ}$ dias (última contagem) de sementes de girassol Embrapa $122-V 2000$ cultivado sob doses de boro

\begin{tabular}{|c|c|c|c|c|c|c|c|}
\hline \multirow{2}{*}{ Boro (kg ha-1) } & \multicolumn{7}{|c|}{ Dias após o florescimento pleno (DAF) } \\
\hline & 7 & 14 & 21 & 28 & 35 & 42 & 49 \\
\hline & \multicolumn{7}{|c|}{ Germinação no $4^{0}$ dia (\%) } \\
\hline 0 & $\begin{array}{l}1,17 \mathrm{a}^{1} \\
(0,48)^{2}\end{array}$ & $\begin{array}{l}1,24 \text { ab } \\
(0,63)\end{array}$ & $\begin{array}{l}1,27 \mathrm{a} \\
(0,73)\end{array}$ & $\begin{array}{l}1,77 \mathrm{a} \\
(2,29)\end{array}$ & $\begin{array}{c}1,51 \mathrm{a} \\
(1,38)\end{array}$ & $\begin{array}{l}2,83 \text { ab } \\
(7,19)\end{array}$ & $\begin{array}{c}3,66 \mathrm{a} \\
(12,94)\end{array}$ \\
\hline 1 & $\begin{array}{l}1,00 \mathrm{a} \\
(0,00)\end{array}$ & $\begin{array}{l}1,34 \text { ab } \\
(0,94)\end{array}$ & $\begin{array}{c}1,53 \mathrm{a} \\
(1,60)\end{array}$ & $\begin{array}{l}1,51 \text { a } \\
(1,56)\end{array}$ & $\begin{array}{l}1,16 \text { a } \\
(0,42)\end{array}$ & $\begin{array}{c}3,22 \mathrm{a} \\
(19,29)\end{array}$ & $\begin{array}{c}4,40 \mathrm{a} \\
(42,29)\end{array}$ \\
\hline 2 & $\begin{array}{l}1,09 \text { a } \\
(0,21)\end{array}$ & $\begin{array}{c}1,65 \mathrm{a} \\
(1,83)\end{array}$ & $\begin{array}{l}1,20 \mathrm{a} \\
(0,63)\end{array}$ & $\begin{array}{c}1,71 \mathrm{a} \\
(2,29)\end{array}$ & $\begin{array}{l}1,29 \mathrm{a} \\
(0,73)\end{array}$ & $\begin{array}{c}2,56 a b \\
(11,88)\end{array}$ & $\begin{array}{c}3,58 \mathrm{a} \\
(24,88)\end{array}$ \\
\hline 3 & $\begin{array}{l}1,04 \text { a } \\
(0,11)\end{array}$ & $\begin{array}{l}1,26 \text { ab } \\
(0,62)\end{array}$ & $\begin{array}{l}1,09 \text { a } \\
(0,21)\end{array}$ & $\begin{array}{c}1,62 \mathrm{a} \\
(1,94)\end{array}$ & $\begin{array}{l}1,28 \text { a } \\
(0,73)\end{array}$ & $\begin{array}{l}2,10 \mathrm{~b} \\
(8,00)\end{array}$ & $\begin{array}{c}3,85 \text { a } \\
(29,67)\end{array}$ \\
\hline 4 & $\begin{array}{l}1,22 \mathrm{a} \\
(0,65)\end{array}$ & $\begin{array}{l}1,00 \mathrm{~b} \\
(0,00)\end{array}$ & $\begin{array}{l}1,18 \mathrm{a} \\
(0,42)\end{array}$ & $\begin{array}{l}2,00 \mathrm{a} \\
(3,47)\end{array}$ & $\begin{array}{l}1,24 \mathrm{a} \\
(0,62)\end{array}$ & $\begin{array}{l}2,30 \mathrm{~b} \\
(9,17)\end{array}$ & $\begin{array}{c}3,41 \mathrm{a} \\
(21,46)\end{array}$ \\
\hline DMS (5\%) & 0,38 & 0,44 & 0,55 & 0,86 & 0,44 & 0,90 & 1,55 \\
\hline $\mathrm{F}$ & $0,91 \mathrm{~ns}$ & $4,56^{\star \star}$ & $1,53 \mathrm{~ns}$ & $0,76 \mathrm{~ns}$ & $1,45 \mathrm{~ns}$ & $3,93^{\star *}$ & $0,99 \mathrm{~ns}$ \\
\hline \multirow[t]{2}{*}{ CV (\%) } & 24,04 & 23,78 & 30,30 & 34,95 & 23,90 & 24,18 & 28,60 \\
\hline & \multicolumn{7}{|c|}{ Germinação no $10^{\circ}$ dia (\%) } \\
\hline 0 & $\begin{array}{c}1,26 \mathrm{a}^{1} \\
(0,67)^{2}\end{array}$ & $\begin{array}{l}2,15 \mathrm{a} \\
(3,94)\end{array}$ & $\begin{array}{l}2,37 \mathrm{a} \\
(4,86)\end{array}$ & $\begin{array}{c}4,15 \mathrm{a} \\
(16,67)\end{array}$ & $\begin{array}{l}1,87 \mathrm{a} \\
(2,81)\end{array}$ & $\begin{array}{c}3,42 \mathrm{a} \\
(10,94)\end{array}$ & $\begin{array}{l}27,43 \mathrm{a} \\
(20,88)\end{array}$ \\
\hline 1 & $\begin{array}{l}1,25 \text { a } \\
(0,71)\end{array}$ & $\begin{array}{c}2,41 \mathrm{a} \\
(10,04)\end{array}$ & $\begin{array}{c}2,39 \text { a } \\
(10,34)\end{array}$ & $\begin{array}{c}3,62 \mathrm{a} \\
(25,04)\end{array}$ & $\begin{array}{c}1,87 \text { a } \\
(5,42)\end{array}$ & $\begin{array}{c}2,64 \mathrm{a} \\
(13,33)\end{array}$ & $\begin{array}{l}28,64 \mathrm{a} \\
(22,17)\end{array}$ \\
\hline 2 & $\begin{array}{l}1,43 \text { a } \\
(1,12)\end{array}$ & $\begin{array}{c}2,78 \text { a } \\
(14,17)\end{array}$ & $\begin{array}{c}2,66 \text { a } \\
(12,92)\end{array}$ & $\begin{array}{c}4,01 \mathrm{a} \\
(31,87)\end{array}$ & $\begin{array}{c}1,79 \mathrm{a} \\
(5,00)\end{array}$ & $\begin{array}{c}2,51 \text { a } \\
(11,04)\end{array}$ & $\begin{array}{l}25,28 \mathrm{a} \\
(17,73)\end{array}$ \\
\hline 3 & $\begin{array}{l}1,32 \mathrm{a} \\
(0,86)\end{array}$ & $\begin{array}{c}2,76 \mathrm{a} \\
(13,92)\end{array}$ & $\begin{array}{c}2,80 \mathrm{a} \\
(14,00)\end{array}$ & $\begin{array}{c}3,98 \text { a } \\
(30,42)\end{array}$ & $\begin{array}{l}2,16 \mathrm{a} \\
(7,92)\end{array}$ & $\begin{array}{c}2,74 \mathrm{a} \\
(13,96)\end{array}$ & $\begin{array}{l}21,58 \mathrm{a} \\
(12,71)\end{array}$ \\
\hline 4 & $\begin{array}{l}1,29 \text { a } \\
(0,75)\end{array}$ & $\begin{array}{c}2,64 \text { a } \\
(12,46)\end{array}$ & $\begin{array}{c}3,03 \text { a } \\
(16,92)\end{array}$ & $\begin{array}{c}3,17 \text { a } \\
(19,38)\end{array}$ & $\begin{array}{c}2,43 \mathrm{a} \\
(10,21)\end{array}$ & $\begin{array}{c}3,24 \text { a } \\
(19,59)\end{array}$ & $\begin{array}{l}24,19 \mathrm{a} \\
(16,25)\end{array}$ \\
\hline DMS (5\%) & 0,49 & 0,85 & 0,84 & 1,13 & 0,81 & 0,94 & 7,08 \\
\hline $\mathrm{F}$ & $0,37 \mathrm{~ns}$ & $1,64 \mathrm{~ns}$ & $1,80 \mathrm{~ns}$ & $2,00 \mathrm{~ns}$ & $1,80 \mathrm{~ns}$ & $2,98 *$ & $2,53 \mathrm{~ns}$ \\
\hline CV (\%) & 26,10 & 23,09 & 22,15 & 20,84 & 27,78 & 22,38 & 19,36 \\
\hline
\end{tabular}

Médias seguidas da mesma letra na coluna não diferem significativamente pelo teste de Tukey

${ }^{1}$ Dados transformados para $(x+1)^{1 / 2} ;{ }^{2}$ Dados originais entre parênteses; ** Significativo a $1 \%$ de probabilidade, ns - Não significativo

não houve diferença entre as doses de boro em todas avaliações (7 aos 42 dias após o florescimento pleno); apenas na penúltima amostragem (42 dias após o florescimento pleno) ocorreu diferença $(\mathrm{P}<0,05)$ pelo teste $\mathrm{F}$, não ocorrendo, no entanto, pelo teste de Tukey no contraste de médias.

Independentemente das doses de boro, a germinação e o vigor das sementes aumentaram com a idade de colheita (Tabela 2). Apesar desses atributos, as doses de boro não exerceram efeito sobre o vigor de sementes de girassol; entretanto, cabe ressaltar que já existia teor médio do micronutriente no solo, na ocasião do plantio. Nota-se a partir da Tabela 2, os valores de germinação registrados no final das avaliações são considerados baixos, de acordo com Albuquerque (2000). Neste sentido se confirma, a dormência existente em sementes recém-colhidas de girassol, fato relatado por Maeda et al. (1987).

Não se verificaram diferenças significativas $(P>0,05)$ entre as doses de boro sobre o teor de óleo nas sementes de girassol. De acordo com Castro et al. (1997) o teor de óleo nos aquênios pode variar de 10 a $60 \%$ e o valor médio registrado no final do experimento foi de 355,2 $\mathrm{g} \mathrm{kg}^{-1}$ (35,52\%).

Dos 7 aos 49 dias após o florescimento do girassol houve incremento de $86,46 \%$ na massa seca média das sementes (9,33 mg para 68,89 mg) e 97,80\% no teor médio de óleo nas sementes (0,08 para $36,44 \%)$; redução de $87,47 \%$ no conteúdo médio de água (89,78 para 11,25 mg por semente) e 83,62\% na concentração de água (877,44 para 143, 69 g por kg de semente). A produtividade média de sementes de girassol foi de $2.559 \mathrm{~kg} \mathrm{ha}^{-1}$.

\section{CONCLUSÕES}

Aos 49 dias após o florescimento pleno as doses de boro aplicadas não influenciaram as características morfofisiológicas das sementes de girassol (dimensões, massa seca, concentração de água, conteúdo de água, primeira contagem da germinação, germinação final, teor de óleo e produtividade), nas condições de teor médio inicial de boro no solo e adequada disponibilidade de água.

\section{LITERATURA CITADA}

Abreu, C. A.; Abreu, M. F.; Raij, B. van; Bataglia, O. C.; Andrade, J. C. Extraction of boron from soil by microwave heating for ICP-AES determination. Comunications in Soil Science and Plant Analysis, v.25, n.19-20, p.3321-3333, 1994. 
Agrianual - Anuário da Agricultura Brasileira. São Paulo: FNP consultoria e comércio. 2005. 520p.

Aitken, R. L.; Jeffrey, A. J.; Comptom, B. L. Evaluation of selected extractants for boron in some Queensland soils. Australian Journal of Soil Research, v.25, p.263-273, 1987.

Albuquerque, M. C. Desempenho germinativo e testes de vigor para sementes de girassol, milho e soja, semeadas sob condições de estresse ambiental. Jaboticabal: FCAV/UNESP, 2000. 180p. Tese Doutorado

Andrade, A. D Ácidos graxos ômega-3 em peixes, óleos de peixes e óleos vegetais comestíveis. Maringá: UEM, 1994. 67p. Dissertação Mestrado

Andrade, S. G. Efeito de lâminas de água e doses de boro na cultura do girassol. Jaboticabal: FCAV/UNESP, 2000. 94p. Tese Doutorado

Banzatto, D. A.; Kronka, S. N. Experimentação agrícola. 4.ed. Jaboticabal: FUNEP, 2006. 237p.

Brasil, Ministério da Agricultura e Reforma Agrária. Regras para análise de sementes. Brasília: SNDA/DNDV/CLAV, 1992. 365p.

Calarota, N. E.; Carvalho, N. M. Efeitos da adubação nitrogenada sobre os conteúdos de óleo e proteína e a qualidade fisiológica de sementes de girassol (Helianthus annuus). Revista Brasileira de Sementes, v.6, n.3, p.41-48, 1984.

Caletti, M. J.; Vázquez-Amábile, G. Evaluación del efecto de la fertilización con boro para híbridos de girasol en suelos Haplustoles Énticos de Gral. Pico, Departamento de Maracó, Prov. de La Pampa. Revista de la Facultad de Agronomia, v.22, n.1, p.45-49, 2002.

Carvalho, N. M. de; Nakagawa, J. Sementes: Ciência, tecnologia e produção. 4. ed. Jaboticabal: FUNEP. cap. 6, p.99, 2000. 588p.

Castiglioni, V. B. R. Fases de desenvolvimento da planta de girassol. Londrina: Embrapa-CNPSo, 1997. 24p. Documentos, 58.

Castro, C. de; Castiglioni, V. B. R.; Balla, A.; Leite, R. M. V. B. C.; Karam, D.; Mello, H. C.; Guedes, L. C. A.; Farias, F. R. B. A cultura do girassol: Tecnologia de produção. Londrina: EMBRAPA-CNPSo, 1997. 36p. Circular Técnica, 67.

Connor, D. J.; Hall, A. J. Sunflower physiology. In: Schneiter, A. A. (ed.). Sunflower technology and production. Madison: ASA, CSSA \& SSSA, 1997. cap. 3, p.113, 182. Monograph, 35.

EMBRAPA - Empresa Brasileira de Pesquisa Agropecuária. Girassol Embrapa 122-V2000. Londrina, 1997. Folder n. 04/97.

EMBRAPA - Empresa Brasileira de Pesquisa Agropecuária. Informes da avaliação de genótipos de girassol, 1998/1999 e 1999. Londrina: Embrapa Soja, 1999. 99p. Documentos, 137.

Fageria, N. K.; Baligar, V. C.; Clark, R. B. Micronutrients in crop production. Advances in Agronomy, v.77, p.185-268, 2002.

Fageria, N. K.; Baligar, V. C.; Jone, C. A. Factors affecting production of field crops In: Growth and mineral nutrition of field crops. New York: Marcel Dekker, 1997. cap. 2. p.11-59.
Hanson, E. How much boron do flowers need? In: Better Crops. Atlanta, v.75, n.4. p.10-11, 1991.

Lima, L. A.; Mischan, M. M.; Neptune, A. M. L. Efeitos isolado e combinado de nitrogênio, fósforo e potássio no desenvolvimento do girassol (Helianthus annuus L.). Anais da Escola Superior de Agricultura Luiz de Queiroz, v.38, n.2, p.857-873, 1981.

Maeda, J. A.; Ungaro, M. R. G.; Lago, A. A.; Razera, L. F. Estádio de maturação e qualidade de sementes de girassol. Bragantia, v.46, n.1, p.35-44, 1997.

Menezes, N. L. de; Marchezan, E. Qualidade de sementes de girassol. Ciência Rural, v.21, n.3, p.337-351, 1991.

Pathak, A. N.; Singh, R. S. Effect of different concentrations of boron in irrigation water on sunflower. Journal of the Indian Society of Soil Science, v.23, p.388-390, 1975.

Quaggio, J. A.; Ungaro, M. R. G. Girassol. In: Raij, B. van.; Cantarella, H.; Quaggio, J. A.; Furlani, A. M. C. Recomendação de adubação e calagem para o estado de São Paulo. 2 ed., Campinas: IAC, 1996. p.198, Boletim Técnico, 100.

Raij, B. van; Andrade, J. C.; Cantarella, H.; Quaggio, J. A. Análise química para a avaliação da fertilidade em solos tropicais. Campinas: IAC, 2001. 285p.

Römheld, V. Aspectos fisiológicos dos sintomas de deficiência e toxicidade de micronutrientes e elementos tóxicos em plantas superiores. In: Ferreira, M. E.; Cruz, M. C. P.; Raij, B. van; Abreu, C. A. (ed.) Micronutrientes e elementos tóxicos na agricultura. Jaboticabal: CNPq/FAPESP/POTAFOS, 2001. cap.4, p.71-86.

Salunke, D. K.; Desai, B. B. Sunflower. Postharvest biotechnology of oil seeds. Boca Raton: CRC Press, 1986. chap.4, p.57-69.

Santos, H. G; Jacomine, P. K.; Anjos, L. H. C.; Oliveira, V. A.; Oliveira, J. B.; Coelho, M. R.; Lumbreras, J. F.; Cunha, T. J. F. (ed.). Sistema de classificação de solos. 2.ed. Rio de Janeiro: Embrapa-Solos, 2006. 306p.

Schneiter, A. A.; Miller, J. P. Description of sunflower stages. Crop Science, v.21, n.6, p.901-903, 1981.

Schon, M. K. Physiological roles of boron in higher plants. Columbia: University of Missouri. 1989, 132p. Ph D Thesis.

Seiler, G. J. Anatomy and morphology of sunflower. In: Schneiter, A. A. (ed.). Sunflower technology and production, Madison: 1997. cap. 3, p.67-111. Monograph, 35.

Silva, M. N. A cultura do girassol. Jaboticabal: FUNEP/UNESP, 1990. 67p.

Ungaro, M. R. G. Girassol (Helianthus annuus L.). Boletim Informativo do Instituto Agronômico, v.200, p.112-113. 1990.

USDA - United States Department of Agriculture- NRCS: Plants Database Classification. http://plants.usda.gov/java/ ClassificationServlet?source $=$ display\&classid =HELIA3. 14 Jun.2006. 